\title{
Micronuclei as biomarkers for evaluating the risk of malignant transformation in the uterine cervix
}

\author{
G.M.A. Aires ${ }^{1}$, J.R.C. Meireles ${ }^{1}$, P.C. Oliveira ${ }^{1}$, J.L. Oliveira ${ }^{1}$, E.L. Araújo ${ }^{2}$, \\ B.C. Pires ${ }^{3}$, E.S.A. Cruz ${ }^{2}$, N.F. Jesus ${ }^{2}$, C.A.B. Pereira ${ }^{4}$ and E.M.M. Cerqueira ${ }^{1}$ \\ ${ }^{1}$ Laboratório de Genética Toxicológica, Departamento de Ciências Biológicas, \\ Universidade Estadual de Feira de Santana, Feira de Santana, BA, Brasil \\ ${ }^{2}$ Centro Municipal de Prevenção ao Câncer Romilda Maltez, \\ Feira de Santana, BA, Brasil \\ ${ }^{3}$ Centro Diagnóstico em Anatomia Patológica, \\ Feira de Santana, BA, Brasil \\ ${ }^{4}$ Departamento de Matemática e Estatística, \\ Universidade de São Paulo, São Paulo, SP, Brasil \\ Corresponding author: J.R.C. Meireles \\ E-mail: jrcmeireles@gmail.com
}

Genet. Mol. Res. 10 (3): 1558-1564 (2011)

Received November 17, 2010

Accepted January 5, 2011

Published August 5, 2011

DOI http://dx.doi.org/10.4238/vol10-3gmr1156

\begin{abstract}
We evaluated micronucleus and apoptosis occurrence among women with normal smears and women with different kinds of cervical abnormalities, i.e., inflammatory processes and low- and high-grade squamous intraepithelial lesions $(\mathrm{N}=12, \mathrm{~N}=10$ and $\mathrm{N}$ $=27$, respectively). The sample included 59 women who were seen at a public medical service for cervical cancer prevention in Feira de Santana, Bahia, Brazil. The diagnosis was established by means of cytological, colposcopic, and histopathological examination. Cytogenetic analysis was performed on 2000 cells from each woman and included assessment of micronuclei and nuclear degenerative
\end{abstract}


abnormalities indicative of apoptosis (karyorrhexis, pyknosis and condensed chromatin). Micronucleus frequency was significantly higher in the women with high-grade squamous intraepithelial lesions than in the women without cervical abnormalities or inflammatory processes $(\mathrm{P}<0.001)$ or in the women with low-grade squamous intraepithelial lesions $(\mathrm{P}<0.005)$. The frequency of apoptosis was similar in women without cervical abnormalities and women showing high-grade squamous intraepithelial lesions $(\mathrm{P}>0.50)$, and significantly lower in women without cervical abnormalities and in women showing high-grade squamous intraepithelial lesions than in women showing inflammatory processes or low-grade squamous intraepithelial lesions $(\mathrm{P}<0.0001)$. These results indicate that, in addition to Papanicolaou cervical cytological analysis, it would be useful to use micronucleus analysis to screen women who are at risk of developing cervical cancer. The assessment of nuclear degenerative abnormalities indicative of apoptosis increased the sensitivity of this test.

Key words: Micronucleus; Apoptosis; LSIL; HSIL

\section{INTRODUCTION}

In spite of preventive measures such as Papanicolaou cervical cytological analysis and, more recently, vaccination against HPV infection, cancer of the uterine cervix continues to be one of the most frequent causes of mortality among women worldwide, particularly in developing countries (Arrossi et al., 2003). In Brazil, cervical malignant neoplasia is the fourth leading cause of death due to cancer, and for 2010, it is estimated that there will be 18,430 cases (INCA, 2009). The cost of evaluating and treating the precursor lesions of uterine cervical cancer, of which many will not develop into invasive cancer, is high (Holowaty et al., 1999). According to Follen et al. (2005), this may be the reason why, in developing countries, cervical cancer goes undetected at higher frequencies than in developed countries.

Infection by oncogenic types of human papillomavirus (HPV), particularly HPV 16 and HPV 18, is the principal risk factor associated with cervical cancer and their precursor lesions, i.e., low- and high-grade squamous intraepithelial lesions (LSIL and HSIL) (Tirado-Gómez et al., 2005). This virus induces structural chromosomal alterations and aneuploidy in the cervical epithelium that are associated with the initiation of the malignant process (Nersesyan, 2007).

Micronucleus assays can detect both of these abnormalities, since micronuclei are formed by chromosomal fragments or whole chromosomes that fail to be included in the nuclei during cell division and remain in the cytoplasm of interphase cells, where they can be observed as structures resembling nuclei (Holland et al., 2008). Several studies have indicated that this test can be used as an auxiliary measure for biologically monitoring women who are at risk of developing cervical cancer (Cerqueira et al., 1998; Leal-Garza et al., 2002; Guzman et al., 2003). In addition, when micronucleus assays are used in accordance with the protocol of Tolbert et al. (1992), they can provide information about the occurrence of apoptosis, which is an event related to the onset of cancer. According to these authors, degenerative nuclear abnormalities such as karyorrhexis, pyknosis and condensed chromatin are endpoints of apoptosis. In the present 
study, occurrences of micronuclei and apoptosis were analyzed in exfoliated cells from the cervix of women without abnormalities and women with different kinds of cervical abnormalities.

\section{MATERIAL AND METHODS}

\section{Sample}

Fifty-nine women who were seen at a public medical service for cervical cancer prevention in Feira de Santana, Bahia, Brazil, agreed to participate in the study. According to the diagnosis, which was obtained by colpocytological, colposcopic and, when indicated, histopathological examination, they were classified into four groups: Group I, formed by 10 women without cervical abnormalities; Group II, formed by 12 women with inflammatory processes; Group III, formed by 10 women with a diagnosis of LSIL, and Group IV, formed by 27 women with a diagnosis of HSIL.

A questionnaire was administered to characterize the women in relation to age, smoking habits and sexual risk factors for developing cervical cancer.

\section{Cytological preparation}

Using material collected from the uterine cervix by means of a cytobrush, smears were placed on clean slides containing two drops of saline solution $(0.09 \% \mathrm{NaCl})$. The smears were fixed using a 3:1 methanol/acetic acid solution for $10 \mathrm{~min}$. Twenty-four hours later, the slides were stained with Schiff reagent and counterstaining with fast green (1\% in ethanol).

\section{Cytogenetic analysis}

The criteria used to identify micronuclei were those described by Sarto et al. (1987). According to these criteria, micronuclei were considered to be distinct structures that have a configuration and staining similar to that of the cell nucleus and are one-fifth to one-third the size of the nucleus (Figure 1A). Degenerative nuclear abnormalities indicative of apoptosis (Figure 1B, C and D) were identified in accordance with Tolbert et al. (1992).
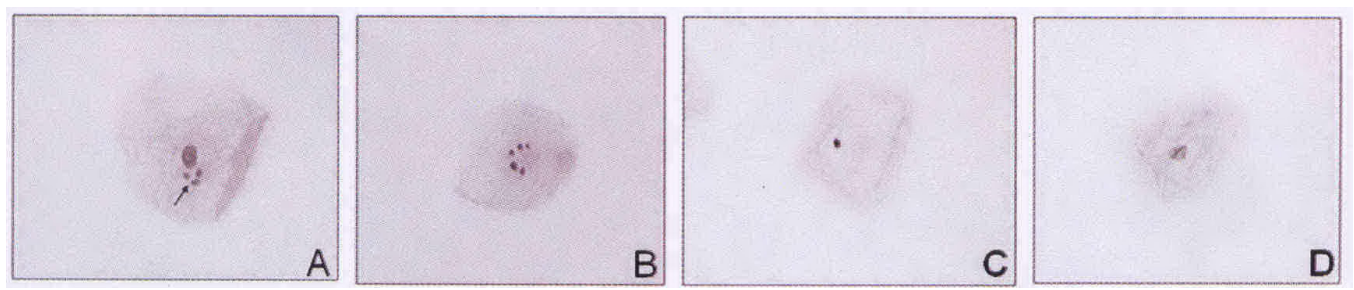

Figure 1. Photomicrographs of exfoliated cells presented micronucleus (A), karyorrhexis (B), pyknosis (C), and condensed chromatin (D).

All analyses were done blindly in relation to data obtained by administering a questionnaire. Two thousand cells were assessed under a light microscope. 


\section{Statistical analysis}

The Kruskal-Wallis test was used to compare quantitative variables, since the data did not show normal distribution. The $\chi^{2}$ test was used for association tables.

To analyze sexual risk factors (number of sexual partners and age at first episode of sexual intercourse), a sex index (SI) was used. This took into consideration not only the number of sexual partners and age at first episode of sexual intercourse, but also the time that had elapsed between the age at first coitus and the age at the time of this study, as established by the formula

$$
\mathrm{SI}=(\mathrm{t} / \mathrm{p})^{2} \times \sqrt{(\mathrm{T}-\mathrm{t})}
$$

in which $\mathrm{T}=$ age, $\mathrm{t}=$ age at first sexual intercourse and $\mathrm{p}=$ number of sexual partners.

The data on micronuclei and degenerative nuclear abnormalities were analyzed using a conditional test for comparing proportions in situations in which events are rare (Bragança-Pereira, 1991).

\section{Ethical matters}

In accordance with Resolution No. 196/1996 of the Brazilian National Health Board, all the participants signed an informed consent statement and full confidentiality was ensured. The study was approved by the Ethics Committee of Feira de Santana State University (Protocol No. 034; 2007).

\section{RESULTS}

\section{Age}

The mean age \pm SE (standard error) for all women was $35.64 \pm 12.33$ years, while for Groups I, II, III, and IV, it was $42.20 \pm 13.59$, $33.75 \pm 12.78,31.00 \pm 10.91$, and $35.77 \pm 11.76$ years, respectively. The Kruskal-Wallis test did not show any differences: $\chi^{2}=5.1080 ; \mathrm{P}>0.1000$.

\section{Sexual behavior}

The differences between groups relating to sexual behavior were evaluated using the SI, with values previously arranged according to the median $(M)$ value $(\mathrm{M}=306.4556)$. No significant difference was observed: $\chi^{2}=6.9246 ; \mathrm{P}>0.05$.

\section{Smoking habits}

Only 10 women said that they were smokers: one in Groups II and III, two in Group I and six in Group IV. Because of the small number of smokers, differences relating to smoking habits could be not analyzed.

\section{Cytogenetic analysis}

The data relating to micronucleus occurrence are presented in Table 1. Differences between the groups were observed: $\chi^{2}=32.4265$. The $\chi^{2}$ partition showed that micronucleus 
occurrence did not differ between the women showing normal smears, inflammatory processes or LSIL, but micronuclei occurred significantly more frequently in the women showing HSIL than in those displaying normal smears, inflammatory processes or LSIL.

\begin{tabular}{|c|c|c|c|c|c|}
\hline Diagnosis & Total cells & $\mathrm{MN}(\mathrm{obs})^{\mathrm{a}}$ & $\mathrm{MN}(\exp )^{\mathrm{b}}$ & $\chi^{2}$ & $\chi^{2}$ partitions (d.f. $=1$ ) \\
\hline NS (a) & 20,000 & 3 & 13.3898 & 32.4265 & (a) $v s(\mathrm{~b})=0.9633 ; \mathrm{P}>0.500$ \\
\hline IP (b) & 24,000 & 7 & 16.0678 & d.f. $=3$ & (a) $v s(\mathrm{c})=2.2727 ; \mathrm{P}>0.050$ \\
\hline $\operatorname{LSIL}(\mathrm{c})$ & 20,000 & 8 & 13.3898 & $\mathrm{P}<0.001$ & (a) vs (d) $=16.1945 ; \mathrm{P}<0.001$ \\
\hline HSIL (d) & 54,000 & 61 & 36.1526 & & $\begin{array}{l}\text { (b) } v s(\mathrm{~d})=13.3828 ; \mathrm{P}<0.001 \\
\text { (c) } v s(\mathrm{~d})=8.3326 ; \mathrm{P}<0.005 \\
\text { (b) vs (c) }=0.3756 ; \mathrm{P}>0.500\end{array}$ \\
\hline Total & 118,000 & 79 & 79 & & \\
\hline
\end{tabular}

The analysis of nuclear abnormalities indicative of apoptosis was done considering the sum of karyorrhexis, pyknosis and condensed chromatin (Table 2). Statistical differences between the groups were found. The $\chi^{2}$ partitions showed that there were significantly fewer occurrences of apoptosis in the women with HSIL than in the women showing inflammatory processes or LSIL. There was no difference between the women with HSIL and the women with normal smears, but apoptosis occurred significantly more frequently in the women with LSIL than in the women with normal smears or inflammatory processes. Apoptosis occurred significantly more frequently in the women showing inflammatory processes than in the women with normal smears.

\begin{tabular}{l} 
Table 2. Apoptosis analysis (karyorrhexis + pyknosis + condensed chromatin). \\
\begin{tabular}{lccccc}
\hline Diagnosis & Total cells & Apop. (obs) & Apop. $(\exp )^{2}$ & $\chi^{2}$ & $\chi^{2}$ partitions (d.f. $\left.=1\right)$ \\
\hline NS (a) & 20,000 & 1,671 & 2,148 & $1,557.8456$ & (a) $v$ (b) $=247.7410 ; \mathrm{P}<0.0001$ \\
IP (b) & 24,000 & 3,207 & 2,578 & d.f. $=3$ & (a) $v$ (c) $=675.6392 ; \mathrm{P}<0.0001$ \\
LSIL (c) & 20,000 & 3,532 & 2,148 & $\mathrm{P}<0.0001$ & (a) $v$ (d) $=3.8288 ; \mathrm{P}>0.0500$ \\
HSIL (d) & 54,000 & 4,264 & 5,800 & & (b) $v s$ (d) $=518.3199 ; \mathrm{P}<0.0001$ \\
& & & & (c) $v s$ (d) $=1,320.6298 ; \mathrm{P}<0.0001$ \\
Total & 118,000 & 12,674 & 12,674 & & (b) $v s$ (c) $=131.5460 ; \mathrm{P}<0.0001$
\end{tabular} \\
\hline
\end{tabular}

${ }^{1}$ Apoptosis observed. ${ }^{2}$ Apoptosis expected. NS = normal smear; IP = inflammatory process; LSIL = low-grade squamous intraepithelial lesion; HSIL = high-grade squamous intraepithelial lesion; d.f. = degrees of freedom.

\section{DISCUSSION}

Cervical cancer is the corollary of a long process that has its onset in LSIL and HSIL precursor lesions. Vaccination against HPV infection and periodical Papanicolaou cervical cytological screening are effective measures for preventing cervical cancer. In spite of the effectiveness of Papanicolaou examinations, Leyden et al. (2005) suggested that to reduce the incidence of cervical cancer further, this test should be improved. Several studies have indicated that there is an association between micronucleus occurrence and progression of precursor lesions of cervical cancer (Cerqueira et al., 1998; Leal-Garza et al., 2002; Guzman et al., 2003). According to Nersesyan (2007), "evaluation of the frequency of micronuclei in exfoliated cervical cells may be an additional criterion for establishing cervical cancer risk and 
the study of micronuclei in Pap smears will increase the sensitivity and specificity of cervical cytology which could impact in diagnostics and secondary prevention of cervical cancer".

The micronucleus occurrences observed in the present study indicate that the frequency of these structures is higher in HSIL, thus corroborating data obtained by other authors. Leal-Garza et al. (2002) and Gandhi and Kaur (2003) observed greater occurrence of micronuclei in women with precursor lesions or cervical cancer than in women showing normal smears. The micronucleus frequency was significantly higher in women with cervical cancer than in women showing precursor lesions, and this finding did not differ between the various stages of cancer progression. However, Campos et al. (2008) described a positive association between micronucleus occurrence and lesion grade. Similar results were reported earlier by Chakrabart and Dutta (1988). Cerqueira et al. (1998) also observed a higher frequency of micronuclei in women showing high-grade precursor lesions, in relation to those with normal smears or LSIL, who did not differ from each other. On the other hand, data obtained by Guzman et al. (2003) showing higher numbers of these structures in women with HSIL did not reach statistical significance.

The data relating to the occurrence of apoptosis are very interesting. As expected, there were more frequent occurrences of endpoints relating to apoptosis in cases of inflammatory process and LSIL, given that both of these are related to this kind of cell response (Sheets et al., 1996; Zhdanov et al., 2003). The significantly lower frequencies of apoptosis in the women with HSIL than in the women showing inflammatory processes or LSIL were indicative of the fact that as the malignant transformation develops, apoptotic response fails to occur (Rogovskaya et al., 2001).

In conclusion, the results described here indicate that the micronucleus assay and Papanicolaou test may be both utilized for screening women who are at risk of developing cervical cancer. The results also suggest that the assessment of degenerative abnormalities indicative of apoptosis increases the sensitivity of this test.

\section{ACKNOWLEDGMENTS}

Research supported by Universidade Estadual de Feira de Santana.

\section{REFERENCES}

Arrossi S, Sankaranarayanan R and Parkin DM (2003). Incidence and mortality of cervical cancer in Latin America. Salud Publica Mex. 45 (Suppl 3): S306-S314.

Bragança-Pereira CA (1991). Teste Estatístico para Comparar Proporções em Problemas de Citogenética. In: Mutagênese, Carcinogênese e Teratogênese: Métodos e Critérios de Avaliação (Rabello-Gay MN, Rodrigues M and MonteleoneNeto R, eds.). Sociedade Brasileira de Genética, Ribeirão Preto, 113-121.

Campos LMFR, Dias FL, Antunes LMG and Murta EFC (2008). Prevalence of micronuclei in exfoliated uterine cervical cells from patients with risk factors for cervical cancer. São Paulo Med. J. 126: 323-328.

Cerqueira EM, Santoro CL, Donozo NF, Freitas BA, et al. (1998). Genetic damage in exfoliated cells of the uterine cervix. Association and interaction between cigarette smoking and progression to malignant transformation? Acta Cytol. 42: 639-649.

Chakrabarti RN and Dutta K (1988). Micronuclei test in routine smears from uterine cervix. Eur. J. Gynaecol. Oncol. 9: 370-372.

Follen M, Crain S, Macaulay C, Basen-Engquist K, et al. (2005). Optical technologies for cervical neoplasia: update of an NCI program project grant. Clin. Adv. Hematol. Oncol. 3: 41-53.

Gandhi G and Kaur B (2003). Elevated frequency of micronuclei in uterine smears of cervix cancer patients. Caryologia 56: $217-222$. 
Guzman P, Sotelo-Regil RC, Mohar A and Gonsebatt ME (2003). Positive correlation between the frequency of micronucleated cells and dysplasia in Papanicolaou smears. Environ. Mol. Mutagen. 41: 339-343.

Holland N, Bolognesi C, Kirsch-Volders M, Bonassi S, et al. (2008). The micronucleus assay in human buccal cells as a tool for biomonitoring DNA damage: the HUMN project perspective on current status and knowledge gaps. Mutat. Res. 659: 93-108.

Holowaty P, Miller AB, Rohan T and To T (1999). Natural history of dysplasia of the uterine cervix. J. Natl. Cancer Inst. 91: $252-258$.

INCA (2009). Ministério da Saúde. Instituto Nacional de Câncer. Estimativa 2010: Incidência de Câncer no Brasil. Available at [http://www.inca.gov.br/estimativa/2010/estimativa20091201.pdf]. Accessed November 15, 2010.

Leal-Garza CH, Cerda-Flores RM, Leal-Elizondo E and Cortes-Gutierrez EI (2002). Micronuclei in cervical smears and peripheral blood lymphocytes from women with and without cervical uterine cancer. Mutat. Res. 515: 57-62.

Leyden WA, Manos MM, Geiger AM, Weinmann S, et al. (2005). Cervical cancer in women with comprehensive health care access: attributable factors in the screening process. J. Natl. Cancer Inst. 97: 675-683.

Nersesyan AK (2007). Possible role of the micronucleus assay in diagnostics and secondary prevention of cervix cancer: a minireview. Cytol. Genet. 41: 317-318.

Rogovskaya SI, Sukhikh GT, Zhdanov AV, Kolobova EA, et al. (2001). Apoptosis in woman uterine cervix in pathologies associated with human papillomavirus. Bull. Exp. Biol. Med. 131: 576-582.

Sarto F, Finotto S, Giacomelli L, Mazzotti D, et al. (1987). The micronucleus assay in exfoliated cells of the human buccal mucosa. Mutagenesis 2: 11-17.

Sheets EE, Crum CP and Yeh J (1996). Association between cervical neoplasia and apoptosis as detected by in situ nuclear labeling. Gynecol. Oncol. 63: 94-100.

Tirado-Gómez LL, Mohar-Betancourt A, López-Cervantes M, García-Carrancá A, et al. (2005). Factores de riesgo de cáncer cervicouterino invasor en mujeres mexicanas. Salud Publica Mex. 47: 342-350.

Tolbert PE, Shy CM and Allen JW (1992). Micronuclei and other nuclear anomalies in buccal smears: methods development. Mutat. Res. 271: 69-77.

Zhdanov AV, Kurbanova DF, Davydova MP, Sosulina LY, et al. (2003). Apoptosis in fimbriae of fallopian tubes and endometrium in pyoinflammatory adnexal diseases. Bull. Exp. Biol. Med. 135: 150-153. 